\title{
sciendo
}

CIVIL AND ENVIRONMENTAL ENGINEERING REPORTS

E-ISSN 2450-8594

CEER 2021; 31 (1): 0093-0105

DOI: $10.2478 /$ ceer-2021-0007

Original Research Article

\section{ANALYSIS OF THE SHEAR RESISTANCE IN THE INDENTED INTERFACE BETWEEN TWO CONCRETE PARTS OF CONCRETE COMPOSITE BEAM}

\author{
Grzegorz SADOWSKI ${ }^{1}$, Piotr WILIŃSKI ${ }^{2}$, Anna HALICKA ${ }^{3}$ \\ 1,2 Warsaw University of Technology, Faculty of Civil Engineering, Mechanics and \\ Petrochemistry, Płock, Poland \\ ${ }^{3}$ Lublin University of Technology, Civil Engineering and Architecture Faculty, Lublin, \\ Poland
}

\begin{abstract}
This paper presents a comparative analysis of shear resistance in the interface between two concrete parts of concrete composite beam. The construction joint was performed as indented one in accordance with Eurocode 2 and fib Model Code 2010. The numerical calculation results were confronted with the actual results of tests of a composite beam subjected to 4-point bending. The displacement values of tested element were obtained using dial sensors and the digital image correlation method (DIC). The analysis shows that the recommendations of Eurocode 2-1-1 and fib Model Code 2010 do not reflect the actual behavior of concrete composite beam with indented surface.
\end{abstract}

Keywords: shear resistance, concrete composite beam

\footnotetext{
${ }^{1}$ Corresponding author: Warsaw University of Technology, Faculty of Civil Engineering, Mechanics and Petrochemistry, 09-400 Płock, ul. Łukasiewicza 17, e-mail: Grzegorz.Sadowski@pw.edu.pl
} 


\section{INTRODUCTION}

The subject of this paper is concrete composite beam consisted of two parts: down part simulating the precast member with indented joint surface and upper layer of new concrete simulating the in-situ concrete. A comparative analysis of the composite beam behaviour under the four-point bending, was carried out using digital image correlation method (DIC) and numerical calculations. The obtained results were confronted with the standard recommendations concerning the calculation of shear resistance at the interface of two concrete - Eurocode 2 [8] (hereinafter as EC2 referred), the fib Model Code 2010 [10] (hereinafter as MC2010 referred) and the analysis of standard methods included in publication [4].

According to EC2, the shear resistance at the interface of two concrete parts is the sum of:

- adhesion, depending on the average tensile strength of the weaker jointed concrete,

- friction, depending on the surface roughness and normal stress resulting from the external load,

- load capacity of stirrups counteracting the stress, resulting from shear friction.

The papers $[3,5,11]$ indicate that the simple summation of these three components is incorrect. The studies presented in the paper [3] show that stress exceeding the $15-20 \%$ of the yield strength appears in stirrups only when the new concrete is separated from the precast element.

Fib Model Code 2010 classifies the joint between concrete parts cast at different times as "rigid" and "non-rigid". A rigid joint characterized by a strong adhesive connection takes place if no or a low stirrups ratio $(\rho<0.05 \%)$ is used and the displacement of concrete parts in relation to each other does not exceed $0.05 \mathrm{~mm}$ until the breaking of the adhesion. The mechanism of destruction of the rigid joint consists in breaking the adhesion and slipping of the connected parts in relation to each other, accompanied by friction. For non-rigid joints (stirrups ratio $\rho>0.05 \%$ and slip between concrete parts ranging from 0.5 to $1.5 \mathrm{~mm}$ ) in MC2010, in addition to the three above-mentioned destruction mechanisms, the dowel action of the stirrups is included. Once the adhesive bond has been broken and the concrete layers are slipped, the main role in shear stress transmission is taken over by friction, shear friction and dowel action.

Both EC2 and MC2010 standards, introduce the "indented construction joint" into the classification of the concrete surfaces. They give the same recommendations for the geometry and spacing of the notches. However, the coefficients used to determine the load capacity component resulting from adhesion are different - in EC2 its value is directly dedicated to the indented construction joint, whereas in MC2010 the coefficient for the indented joint is of the same value as for a very rough surface. 
The aim of this paper is to widen the knowledge on the destruction mechanism of concrete composite beams with the indented construction joint of different geometry and to find out whether the methods given in EC2 and MC2010 reflect the actual behaviour of such composite elements.

\section{MATERIALS AND METHODS}

\subsection{Preparation of elements for testing}

The tested composite beam consisted of a precast element of $3000 \times 150 \times 250 \mathrm{~mm}$ in dimensions and the indented upper surface with notches in $80 \mathrm{~mm}$ spacing and $70 \mathrm{~mm}$ thick layer of new concrete. The surface geometrical characteristic is shown in Figure 1.

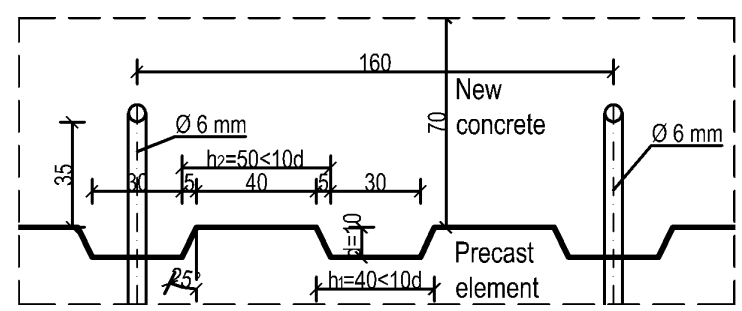

Fig. 1. Precast indented surface with notches

The precast elements were made of ready-mix C25/30 concrete made with use of CEMI 42.5R cement. The main (bottom) reinforcement constituted the $3 \varnothing 20 \mathrm{~mm}$ ribbed bars made of B500B steel. Ribbed $\varnothing 8 \mathrm{~mm}$ stirrups made of B500B steel were used at $80 \mathrm{~mm}$ spacing in the support zones $(1120 \mathrm{~mm}$ long), while in the remaining part of beam their spacing was equal to $110 \mathrm{~mm}$. Concrete layers were connected by a joining reinforcement consisted of two-armed $\varnothing 6 \mathrm{~mm}$ ribbed stirrups made of B500B steel at $160 \mathrm{~mm}$ spacing. The dimensions and reinforcement of beam were shown in Figure 2. 


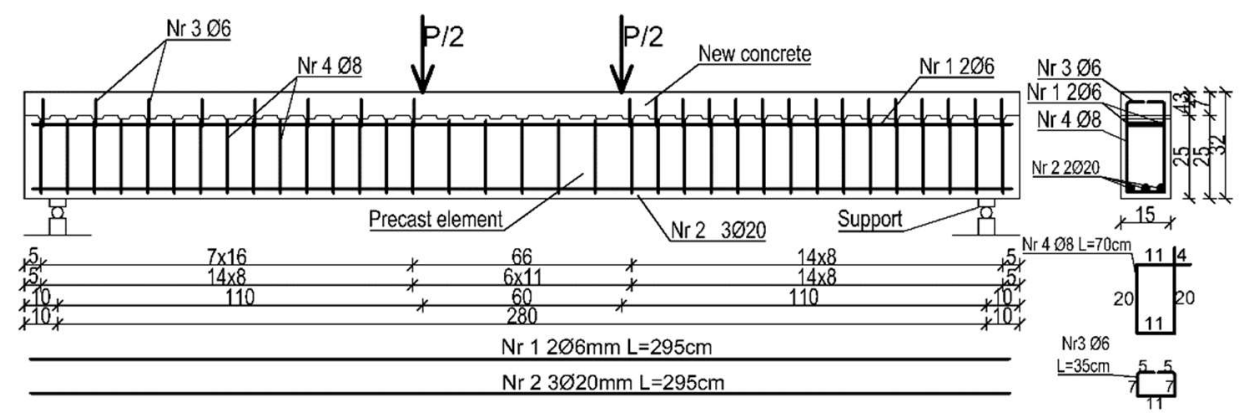

Fig. 2. Dimensions and reinforcement scheme for composite beam

New concrete layer was laid after 71 days of precast concrete curing. It was made of CEM II/B-V 32.5N-LH/HSR/NA cement (producer Grupa Ożarów S.A.), fine 0-4 $\mathrm{mm}$ aggregate and gravel of 4-16 $\mathrm{mm}$. In order to obtain an appropriate consistency of the concrete mix BETOCRETE-F27 (FM) liquefying admixture in the amount of $1 \%$ of cement mass was used. The tap water was used. The class of new concrete was determined in accordance with PN-EN 206+A1: 2016-12 [7] as $\mathrm{C} 25 / 30$ and the consistency class as F4.

During each concreting, samples were made to determine the concrete compressive strength $(10$ samples $150 \times 150 \times 150 \mathrm{~mm})$ and tensile strength by splitting ( 6 samples $150 \times 150 \times 150 \mathrm{~mm}$ ) and elasticity modulus ( 3 cylinders $\phi 150$ $\mathrm{mm}, \mathrm{h}=300 \mathrm{~mm}$ ). The beams and samples were stored in the laboratory for 113 days (precast element) and 42 days (new concrete) until testing in air-dry conditions. The determined material parameters used to the analysis were shown in Table 1.

Table 1. Material parameters of concrete and structural steel

\begin{tabular}{|c|c|c|c|c|c|c|}
\hline \multicolumn{3}{|c|}{ Concrete } & \multicolumn{3}{c|}{ Steel } \\
\hline & $\begin{array}{c}f_{c m . c u b e} \\
{[M P a]}\end{array}$ & $\begin{array}{c}f_{c t m} \\
{[M P a]}\end{array}$ & $\begin{array}{c}E_{c m} \\
{[G P a]}\end{array}$ & & $f_{y}$ \\
{$[M P a]$} & $\begin{array}{c}E_{S} \\
{[G P a]}\end{array}$ \\
\hline New concrete & 43.57 & 2.40 & 31.85 & stirrups $\phi 6$ & 545 & 200 \\
\hline $\begin{array}{c}\text { Precast } \\
\text { concrete }\end{array}$ & 36.30 & 2.30 & 27.99 & stirrups $\phi 8$ & 545 & 200 \\
\hline
\end{tabular}

\subsection{Description of the laboratory stand}

Diagram of the composite beam, arrangement of sensors and zones recorded by digital cameras are shown in Figure 3. The stand was equipped with Sylvac S_dial SWISS MODE electronic dial sensors for measuring the deflections (sensors 79), strain in the middle of the span (sensors $2-6$, measuring base $\sim 200 \mathrm{~mm}$ ), supports displacements (sensors 10-13). The value of load $\mathrm{P}$ was read from the 
dynamometer (sensor 1). The load was applied to the element monotonously with the speed of about $2.7 \mathrm{kN} / \mathrm{min}$ until the element was damaged. The measurement results were recorded continuously at a frequency of 1 second and recorded in the data sheet.

Simultaneously, photos necessary for image analysis were taken. Figure 3 shows the locations of photos (I - zone photographed by the camera no. 1, II - zone photographed by the camera no. 2, III - zone photographed by the camera no. 3 ). The dial sensors were located on the opposite side of beam in relation to the photographed zones.

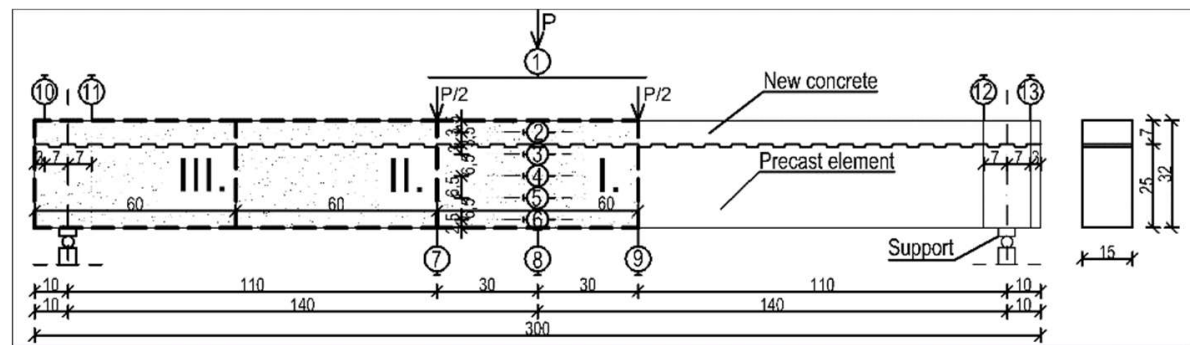

Fig. 3. The scheme of tested composite beam: position of dial indicators (1-13) and location of zones recorded by digital cameras (I. - III.)

\subsection{Description of the digital image correlation method (DIC)}

The image of the beam changing in destruction process was analysed using the digital image correlation method (DIC). The one side of test elements was prepared by painting with white paint and then applying the pattern of black dots, which are markers used in the process of image processing.

Three 24-megapixel digital cameras with APS-C size CMOS sensors were used. Each of them took photos of a part of beam surface of approximately $320 \times 600$ $\mathrm{mm}$ (as shown in Figure 3). The photos were taken automatically every 20 seconds, and the synchronization with dial sensor results was achieved by correlating the internal time of digital cameras with a computer. Due to the fact that each analysed fragment of the beam was photographed with one camera, the analysis of photos was conducted using the 2D digital image correlation method. The use of lenses with APS-C matrices aimed at minimizing optical defects (among others, distortions and spherical aberrations were minimized).

Obtained images were analysed using GOM Correlate software. The software operates on the principle of correlation and searching for elements with identical shapes and determining the change of their coordinates. To the characteristic points of analysed image, the software assigns square or rectangular areas called "facets", which sizes are usually 15 x 15 pixels. In each assigned area there is a 
unique pattern, which is directly used to analyse displacements and deformations. A detailed description of the operation principle of DIC method, preparation and execution of tests and inaccuracies of the method can be found in publications [1, $6,7,12-14]$.

\section{RESULTS}

\subsection{Results of laboratory tests}

Figure 4 shows the recorded displacements of beam analysed using GOM Correlate at different load levels.

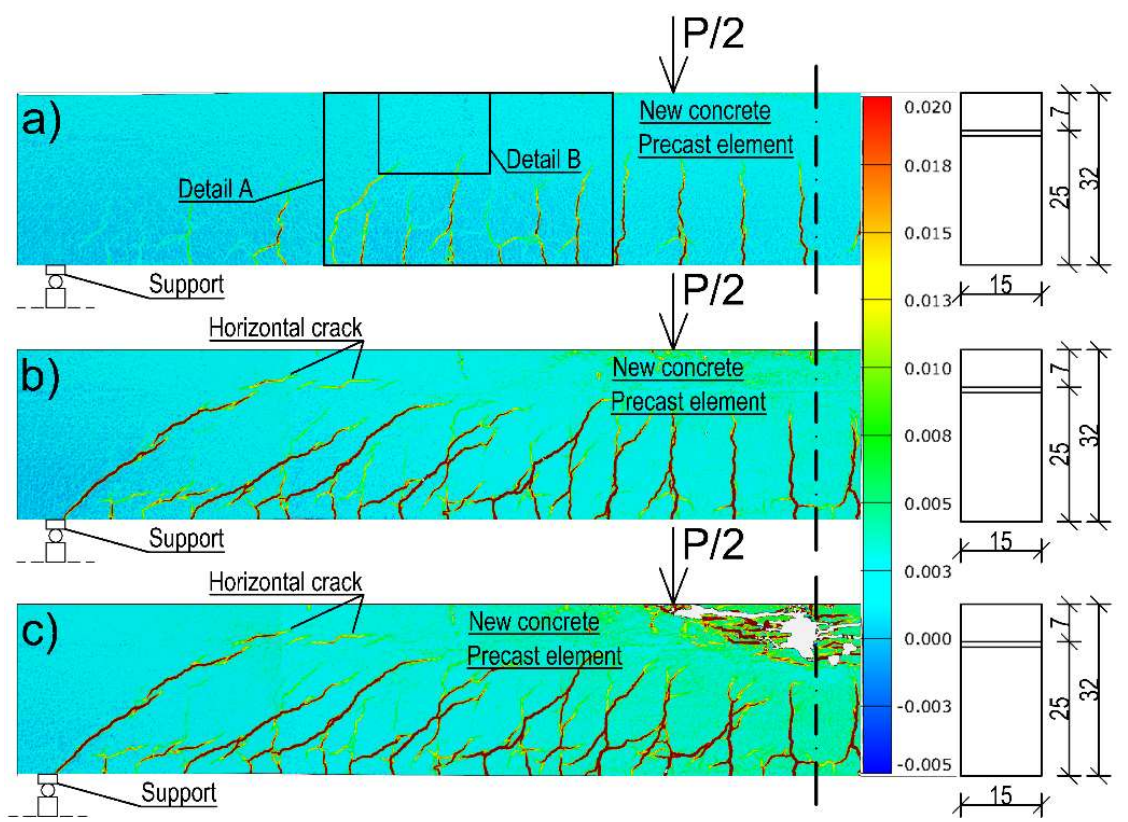

Fig. 4 Cracks pattern of the composite beam obtained with the GOM Correlate software analysing the $\mathrm{Y}$-axis displacements, a) $\mathrm{P}=100.2 \mathrm{kN}$, b) $\mathrm{P}=180 \mathrm{kN}$, c) $\mathrm{P}=198.7 \mathrm{kN}$

The mechanism of beam destruction was as follows. The first vertical cracks in the pure bending zone appeared under a load of $9.5 \mathrm{kN}$, and diagonal cracks in the constant transverse force zone occurred under the load of $80 \mathrm{kN}$. The first crack between the precast element and new concrete layer also appeared in the constant transverse force zone under the load of $100.2 \mathrm{kN}$. This interface crack appeared in the horizontal plane of notch on its one side, as shown in Figures 4a and 5. At that time numerous bending cracks and the first diagonal shear cracks existed yet, but the interface crack was independent of them. As the load increased, the first interface crack extended and widened, and new interface cracks formed at the subsequent notches towards the support, as shown in Figure 4b. Figure 4c shows 
the element displacement under the ultimate load of $198.70 \mathrm{kN}$. The beam was destroyed as a result of concrete compression in the upper part of section (crushing of the concrete), as shown in Figure 6. Delamination of the new concrete from precast element along the entire beam length, was not observed.
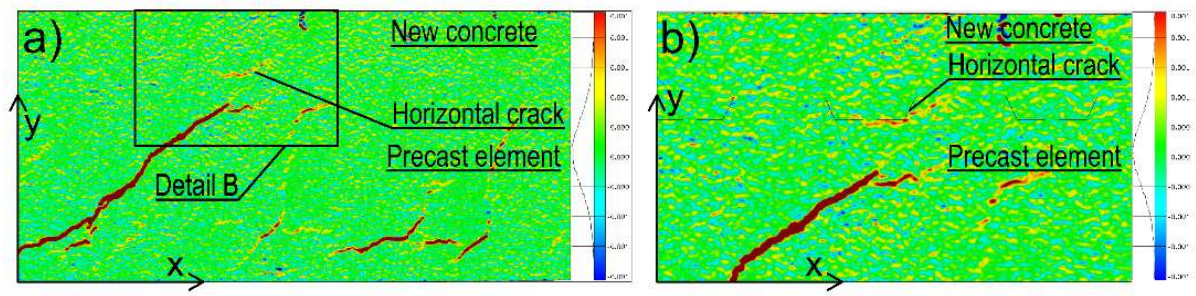

Fig. 5. Cracks pattern of the composite beam obtained with the GOM Correlate software analysing the $\mathrm{Y}$-axis displacements, a) detail A under $100.2 \mathrm{kN}$ load as shown in Figure $4 \mathrm{a}, \mathrm{b}$ ) detail $\mathrm{B}$ under $100.2 \mathrm{kN}$ load as shown in Figure 5a
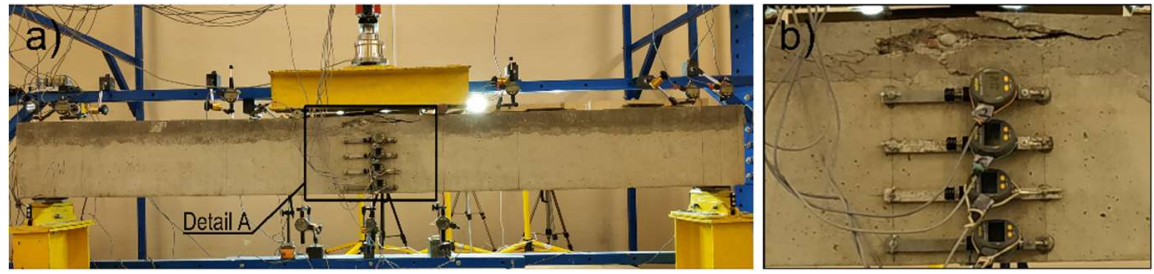

Fig. 6. View of test item after test (own photo), a) general view, b) detail - A

\section{DISCUSSION}

\subsection{Calculation of shear resistance and shear stress in the interface between concrete parts cast at different times}

The shear resistance calculations were conducted in accordance with EC2 and MC2010 standards.

The design value of the interface shear resistance in EC2 is given by the equation:

$$
v_{\mathrm{Rdi}}=c f_{\mathrm{ctd}}+\mu \sigma_{\mathrm{n}}+\rho f_{\mathrm{yd}}(\mu \sin \alpha+\cos \alpha) \text {, }
$$

but not more than $0,5 v f_{\mathrm{cd}}$

where:

$c, \mu$ - factors depending on the roughness of the interface (according to point 6.2.5 EC2 $c=0.5$ for the surface with notches, while $\mu=0.6$ is adopted for smooth surface),

$f_{c t d}$ - design value of concrete tensile strength, 
$f_{c d}$ - design value of concrete compressive strength,

$\sigma_{n}$-stress caused by the minimum external force normal to the interface,

$v$-strength reduction factor for concrete cracked in shear, according to point 6.2.2 of the standard [8],

$\rho$ - ratio of the reinforcement crossing the interface (for the tested element $\rho=0.24 \%$,

$\alpha$-slope angle of the reinforcement crossing the interface (for the tested element $\alpha=90^{\circ}$.

The upper limit value was $0,5 v f_{\mathrm{cd}}=6,17 \mathrm{MPa}$ and is significantly greater than $v_{\mathrm{Rdi}}$. According to MC2010, the design shear resistance at the interface must be determined by the following equation:

$$
\tau_{\mathrm{Rdi}}=c_{r} f_{c \mathrm{k}}^{1 / 3}+\mu \sigma_{\mathrm{n}}+\kappa_{1} \rho f_{\mathrm{yd}}(\mu \sin \alpha+\cos \alpha)+\kappa_{2} \rho \sqrt{f_{\mathrm{yd}} f_{\mathrm{cd}}} \leq \beta_{c} v f_{\mathrm{cd}}
$$

where:

$c_{r}$ - coefficient of influence of aggregate interlock (the value for the rough contact $c_{r}=0.2$ was adopted),

$\kappa_{1}$ - coefficient of efficiency for tensile force that can be activated in the reinforcement (the value for the surface with notches $\kappa_{l}=0.5$ was adopted),

$\kappa_{2}$ - coefficient for flexural resistance of reinforcement (the value for smooth surface according to Table 7.3-2 of the Standard [10] $\kappa_{2}=1.1$ was adopted),

$\mu$ - coefficient of friction (the value for smooth surface according to table 7.3-2 MC2010 $\mu=0.6$ was adopted),

$\beta_{c}-$ coefficient allowing for angle of diagonal concrete strut $\left(\beta_{c}=0.5\right.$ was adopted).

Limit shear stress of the interface $\beta_{\mathrm{c}} \nu \mathrm{f}_{\mathrm{cd}}=6.24 \mathrm{MPa}$ are much bigger than $\tau_{\mathrm{Rdi}}$. It was assumed that the interface at the beam points under consideration is not loaded with an external load, thus in formulae (4.1) and (4.2) $\mu \sigma_{n}=0$ was adopted. From the paper [5] it can be concluded that normal stresses, perpendicular to the interface in the beam loaded with concentrated forces are created also in places out of forces region. Due to difficulties in their determination and their local range, they were omitted at this stage of analysis.

The design shear resistance according to EC2 and MC2010 standards was calculated using the actual values of material parameters listed in Table 1.

The design value of the shear stress in the interface was determined from the relation contained in both $\mathrm{EC} 2$ and MC2010.

$$
v_{\mathrm{Edi}}=\beta \frac{V_{\mathrm{Ed}}}{z b_{\mathrm{i}}},
$$

in which:

$\mathrm{V}_{\mathrm{Ed}}$ - transverse shear force, 
$\mathrm{z}$ - lever arm of composite section; this value, determined from the position of compression zone centre of gravity according to figure 7 is equal to $25.53 \mathrm{~cm}$, while calculated according to the standard recommendations $0.9 \mathrm{~d}=$ $25.83 \mathrm{~cm}$,

$b_{i}-$ width of the interface $\left(b_{i}=15 \mathrm{~cm}\right)$,

$\beta$ - the ratio of the longitudinal force in the new concrete and the total longitudinal force either in the compression or tension zone, both calculated for the section considered.

In order to determine $\beta$ coefficient, the range of compression zone, was determined in the section where the delamination between the precast element and new concrete occurred (Figure $4 \mathrm{a}$ and Figure 5). This range was obtained from the analysis of deformations recorded with "virtual" strain gauges using GOM Correlate software [2] as shown in Figure 7. The characteristic value of the shear stress in the interface was calculated for a $180 \mathrm{kN}$ load close to the ultimate load (Figure 4b).
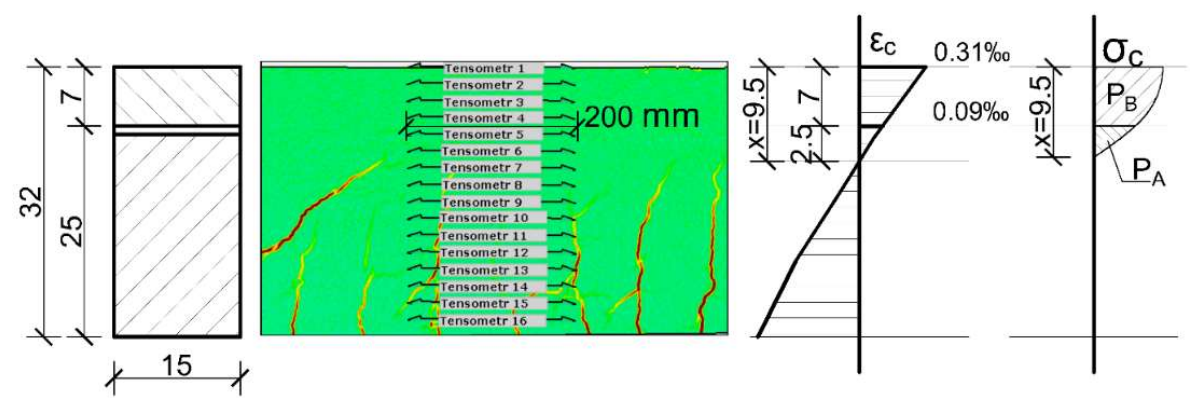

Fig. 7. Diagram of "virtual strain gauges" location in the second zone of image recording (see Fig. 3), $\varepsilon_{c}$ strain distribution under $\mathrm{P}=100.2 \mathrm{kN}$ determined with these gauges and the $\sigma_{\mathrm{c}}$ stress distribution (based on the EC2-1-1 $\sigma_{\mathrm{c}^{-}} \varepsilon_{\mathrm{c}}$ relationship) used for calculation of the $\beta$ coefficient

Based on deformations of the "virtual strain gauges" and assuming a parabolicrectangular $\sigma_{\mathrm{c}}-\varepsilon_{c}$ relationship according to $[8,11]$, the values of longitudinal force in the new concrete $\left(P_{B}\right)$ and precast element $\left(P_{A}\right)$ were calculated by integrating the appropriate part of the stress block (Figure 7). The ratio of longitudinal force $P_{B}$ and the total longitudinal force in the compression zone $\left(P_{A}+P_{B}\right)$ expressed the $\beta$ coefficient value.

Table 2 shows the characteristic values shear resistance of the interface according to EC2 and MC2010. It was determined as the sum of individual components according to formulas (4.1) and (4.2), i.e. for the concrete strength, yield strength of stirrups and dowel action. For comparison with the characteristic of the shear 
stress obtained in tests, characteristic value of shear resistance of the interface was calculated, assuming:

- characteristic values of material parameters instead of $f_{c t m}$ and $f_{y d}$ in formula (4.1)

- the first component related to interlocking of aggregates multiplied by the material factor 1.4 to obtain $1.4 \mathrm{c}_{\mathrm{r}} \mathrm{f}_{\mathrm{ck}}^{1 / 3}$ and in the other components characteristic values $f_{c k}$ and $f_{y k}$ in formula (4.2).

Calculation of the interface shear stress was conducted for the load causing the first crack between the precast element and new concrete $(100.2 \mathrm{kN})$ and for $180 \mathrm{kN}$ load.

Table 2. Characteristic values of shear resistance at the interface

Shear resistance at the interface according to fib Model Code $2010 \tau_{\text {Rdi }}[\mathrm{MPa}]$

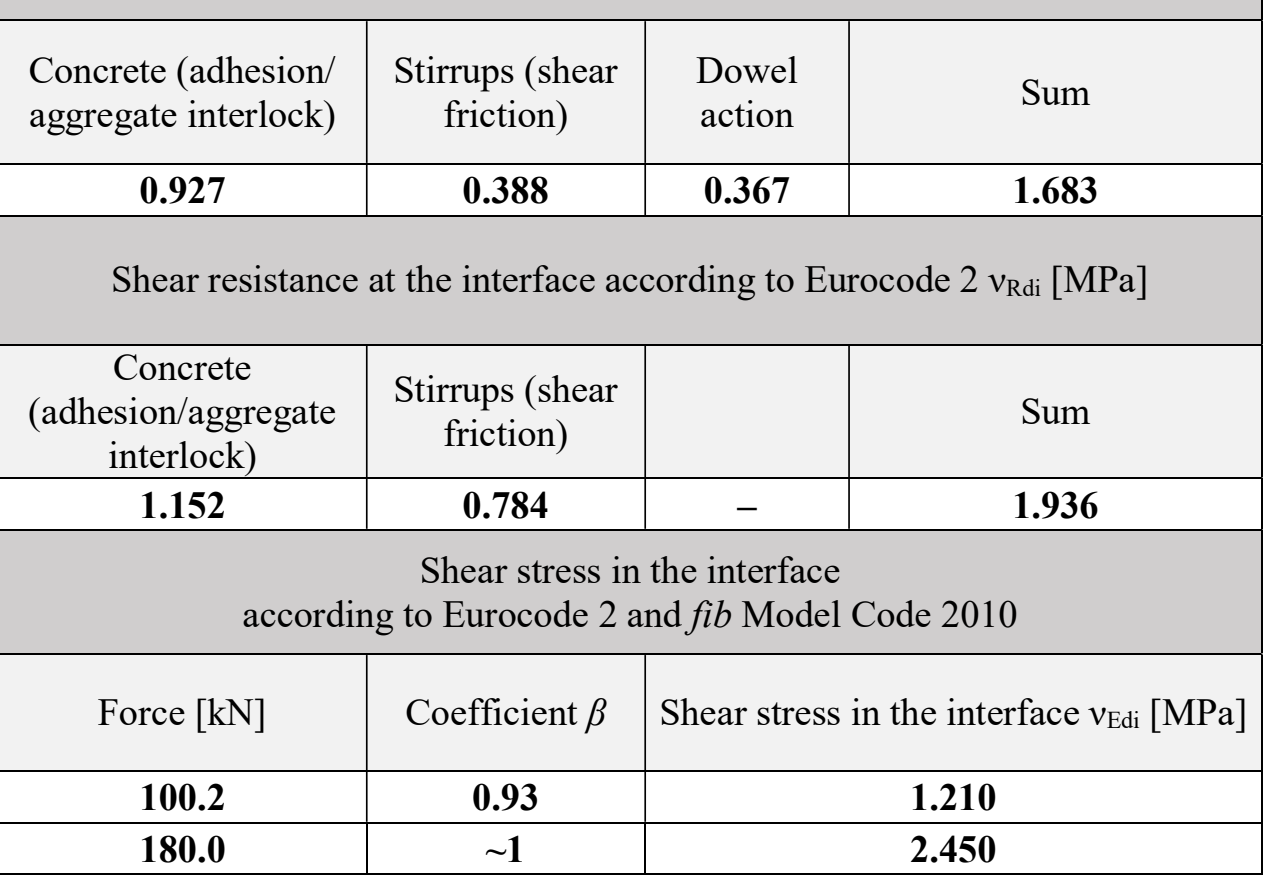

\subsection{Analysis of the test results and the calculated interface shear stress}

The characteristic value of shear resistance of the indented reinforced interface calculated for the analysed composite beam, according to EC2 is $15.03 \%$ higher than calculated according to MC2010. Fib Model Code 2010 significantly changes the calculation of the design shear resistance of the interface with joining reinforcement. The concrete contribution into design shear resistance (adhesion / 
aggregate interlock) according to EC2 is $24.27 \%$ is higher than that calculated according to MC2010. This is due to the fact that MC2010 does not differentiate the coefficients for joints with notches and very rough ones and the impact factor $c_{r}$ of aggregate interlock for the notches should be adopted as for the very rough surface. With regard to the component resulting from the reinforcement, the coefficient of efficiency $\kappa_{1}$ in MC2010 reduces the load capacity component resulting from the shear friction by $50.51 \%$ compared to Eurocode. The sum of dowel action and shear friction calculated according to MC2010 is slightly lower (by $3.70 \%$ ) in comparison with the EC2 calculation.

The characteristic value of the shear stress in the interface according to EC2 and MC2010 is calculated from the formula (4.3). Table 2 shows the values of shear stress for $100.2 \mathrm{kN}$ load, in which separation of new concrete from the precast element was optically observed, and for $180 \mathrm{kN}$ load, are close to ultimate load.

The interface shear stress under $100.2 \mathrm{kN}$ load is equal to $1.21 \mathrm{MPa}$. It is slightly higher than the design shear resistance of the interface due to concrete only, calculated according to EC2 $(1.152 \mathrm{MPa})$, which results in the cracks between layers in tested beam.

In the analysed section, under a load of $100.2 \mathrm{kN}$, at the moment of interface cracking (breaking of adhesion between concrete) the shear stress reaches its maximum value. The cracks pattern is followed by slippage of layers in relation to each other, blocked by the existence of diagonal notch surfaces, while shear friction and dowel action due to stirrups have less contribution to the characteristic of interface shear resistance $[3,5]$.

Under the $180 \mathrm{kN}$ load, close to the ultimate load, the shear stress in the interface is equal to $2.45 \mathrm{MPa}$. Due to the fact that the beam was destroyed by bending, it can be concluded that the interface load capacity was higher. The values of the obtained shear stress in the interface are close to the characteristic interface shear resistance according to EC2. The obtained characteristic shear resistance according to MC2010 is $31.31 \%$ less than the characteristic of the shear stress calculated at $180 \mathrm{kN}$ load. The big difference between the values may be caused by assigning coefficient of the surface with notches to a very rough surface.

In the test, the beam was destroyed by bending and not by reaching the resistance in the interface, and therefore it can only be concluded that the joint load capacity was greater than the obtained ultimate load.

By analysing the imaging method and calculation results, it can be concluded that for composite elements with the indented interface, the EC2 and MC2010 formulas do not reflect the actual behaviour of joints between concrete parts. Assignment of the indented surface to a very rough surface in the fib Model Code 2010 leads to a significant underestimation of the characteristic of interface shear resistance. 
Both standard [8] and comment [10] provide general guidance on the geometry of the indented construction joint. In further studies, the authors would like to point out that the spacing and height of notches may have a significant impact on the characteristic of the interface shear resistance. In addition, it should also be pointed out that the surface of notches may be characterized by a different roughness coefficient, which may result in variation of joint between concrete parts performance.

\section{CONCLUSION}

The following conclusions regarding the performance of indented interface in composite concrete beam can be formulated on the basis of the observations with the image method and the calculation results:

- destruction of tested beam occurred in bending and the characteristic of interface shear resistance was not achieved, which leads to the conclusion that the joint load capacity was greater than ultimate load,

- studies showed a progressive, but local, character of the interface cracking, which appeared horizontally in the lower plane of one of the notches in support zone, and then with an increase in load in subsequent notches,

- the characteristic value of shear resistance at the interface both according to PN-EN 1992-1-1:2008 and fib Model Code 2010 was lower than obtained in tests,

- the assumption in MC2010 of a roughness coefficient for notched surface identical to that assigned to very rough one significantly underestimates the interface shear resistance, while the introduction of dowel action in MC2010 more accurately reflects the mechanism of joints than in EC2,

- problem of performance of the composite beams with indented construction joint requires further studies concerning the impact of shape and size of notches on the interface cracking and characteristic of interface shear resistance.

\section{ACKNOWLEDGEMENT}

The paper was elaborated as a part of scientific research financed from the statutory funds of the Faculty of Civil Engineering, Mechanics and Petrochemistry of the Warsaw University of Technology.

\section{REFERENCES}

1. Aggelis, DG, Verbruggen, S, Tsangouri, E, Tysmans, T and Van Hemelrijck, D 2013. Characterization of mechanical performance of concrete beams with 
external reinforcement by acoustic emission and digital image correlation. Construction and Building Materials 47, 1037-1045.

2. GOM Corellate [Access: 15.12.2018], [Online:] http://www.gom.com/3dsoftware/gom-correlate/download.html.

3. Halicka, A 2007. A study of the stress-strain state in the interface and support zones of composite structures with shrinkable and expansive concretes (in Polish). Lublin: Wydawnictwo Uczelniane.

4. Halicka, A and Jabłoński, $Ł$ 2015. The joint of two concrete members of different ages - parameters and capacity according to fib Model Code 2010 (in Polish). Inżynieria i Budownictwo 7, 346-350.

5. Jabłoński, Ł 2018, Influence of surface parameters on static performance of concrete composite t-shaped beams (in Polish). Lublin: Wydawnictwo Uczelniane.

6. Kowalewski, ZL, Dietrich, L, Kopeć, M, Szymczak, T and Grzywna, P 2016. Modern optical systems in mechanical testing - construction, operations, applications (in Polish). XII Seminarium Nieniszczące Badania Materiałowe, Zakopane, Polska, Marzec, 16-18, 1-32.

7. Krawczyk, Ł, Gołdyn, M and Urban, T 2017. About inaccuracies of dic system (in Polish). Journal of Civil Engineering, Environment and Architecture 64, 259-270.

8. PN-EN 1992-1-1:2008 Eurokod 2: Design of concrete structures - Part 1-1: General rules and rules for buildings.

9. PN-EN 206+A1:2016-12, Concrete-Specification, Performance, Production and Conformity.

10. Walraven, JC, and Ajdukiewicz, A (tł.) 2014. fib Model Code 2020 for concrete structures. Kraków: Wydawnictwo Polski Cement.

11. Sadowski, G and Wiliński, P 2017. Study of influence of surface shape on deflection concrete beams cast in two stages (in Polish). Inżynieria $i$ Budownictwo 4, 206-210.

12. Sadowski, G and Wydra, M 2019. Comparison of methods applied to analysis of crack propagation in reinforced concrete composite beam (in Polish). Acta Scientiarum Polonorum Architectura 1, 3-12.

13. Szczecina, M, Tworzewski, $P$ and Uzarska, I 2018. Numerical modeling of reinforced concrete beams, including the real position of reinforcing bars. Structure and Environment 1, 28-38.

14. Tsangouri, E, Aggelis, DG, Van Tittelboom, K, De Belie, N and Van Hemelrijck D 2013. Detecting the activation of a self-healing mechanism in concrete by acoustic emission and digital image correlation. The Scientific World Journal, 1-10.

Editor received the manuscript: 17.11.2020 